\title{
Determining novel functions of Arabidopsis 14-3-3 proteins in central metabolic processes
}

\author{
Celine Diaz ${ }^{1}$, Miyako Kusano ${ }^{1}$, Ronan Sulpice ${ }^{2}$, Mitsutaka Araki ${ }^{1}$, Henning Redestig ${ }^{1}$, Kazuki Saito ${ }^{1}$, Mark Stitt ${ }^{2}$ and \\ Ryoung Shin ${ }^{1 *}$
}

\begin{abstract}
Background: 14-3-3 proteins are considered master regulators of many signal transduction cascades in eukaryotes. In plants, 14-3-3 proteins have major roles as regulators of nitrogen and carbon metabolism, conclusions based on the studies of a few specific 14-3-3 targets.

Results: In this study, extensive novel roles of 14-3-3 proteins in plant metabolism were determined through combining the parallel analyses of metabolites and enzyme activities in 14-3-3 overexpression and knockout plants with studies of protein-protein interactions. Decreases in the levels of sugars and nitrogen-containing-compounds and in the activities of known 14-3-3-interacting-enzymes were observed in 14-3-3 overexpression plants. Plants overexpressing 14-3-3 proteins also contained decreased levels of malate and citrate, which are intermediate compounds of the tricarboxylic acid (TCA) cycle. These modifications were related to the reduced activities of isocitrate dehydrogenase and malate dehydrogenase, which are key enzymes of TCA cycle. In addition, we demonstrated that 14-3-3 proteins interacted with one isocitrate dehydrogenase and two malate dehydrogenases. There were also changes in the levels of aromatic compounds and the activities of shikimate dehydrogenase, which participates in the biosynthesis of aromatic compounds.
\end{abstract}

Conclusion: Taken together, our findings indicate that 14-3-3 proteins play roles as crucial tuners of multiple primary metabolic processes including TCA cycle and the shikimate pathway.

\section{Background}

14-3-3 proteins are known to regulate diverse processes via binding phosphorylated target proteins in all eukaryotes [1-5]. Although hundreds of potential 14-3-3interacting proteins have been identified $[1,5]$, there have been limited studies that confirm in vivo interactions and/or elucidate the regulating functions of 14-3-3 proteins [6-10]. The most intensively characterized 143-3 target proteins are nitrate reductase and $\mathrm{H}^{+}$-ATPase. 14-3-3 proteins activate $\mathrm{H}^{+}$-ATPase [11] and inhibit nitrate reductase activity [12]. Our previous study suggests that three 14-3-3 isoforms (kappa, chi and psi) also play important roles in nitrogen and sulfur metabolic processes by regulating the activities of phosphoenolpyruvate carboxylase and O-acetylserine lyase [13].

Plant 14-3-3 proteins are mainly thought to be regulators of carbon and nitrogen metabolism [2]. However,

\footnotetext{
* Correspondence: rshin@psc.riken.jp

${ }^{1}$ RIKEN Plant Science Center, Yokohama, Kanagawa 230-0045, Japan

Full list of author information is available at the end of the article
}

this assumption is based on studies of only a few target proteins, such as nitrate reductase and sucrose-phosphate synthase [14]. Nitrate reductase is phosphorylated in the dark by the calcium-dependent protein kinase (CDPK) and the sucrose non-fermenting related kinase 1 (SnRK1) that initiates the interaction of the enzyme with the 14-3-3 proteins and its inactivation. In the light, nitrate reductase is dephosphorylated by a protein phosphatase 2A, leading to the dissociation of the 14-33 and the activation of nitrate reductase [15-18]. In carbon metabolism, some carbon metabolic enzymes such as sucrose phosphate synthase [19], and the dual function protein 6-phosphofructo-2-kinase/fructose-2,6bisphosphatase [20], have been identified as interacting targets of 14-3-3 proteins. The functional relevance of 14-3-3 proteins in the regulatory mechanism of their targets, however, is still not clear. Considering the hundreds of possible 14-3-3 target proteins revealed through multiple screening studies, the roles so far described are
C Biomed Central

(c) 2011 Diaz et al; licensee BioMed Central Ltd. This is an Open Access article distributed under the terms of the Creative Commons Attribution License (http://creativecommons.org/licenses/by/2.0), which permits unrestricted use, distribution, and reproduction in any medium, provided the original work is properly cited. 
likely to be only a small part of the functions of 14-3-3 proteins $[5,13,21]$.

Metabolite profiling is a powerful tool that has contributed to the understanding of plant physiology, including phenotypic differences, gene annotations, metabolite regulation, and characterization of stress responses [22,23]. Moreover, the integration of metabolomics with other 'omics,' such as genomics, enzymomics, and interactomics, leads not only to construction of metabolic networks but also to understanding the roles particular proteins play within the metabolic network $[24,25]$. In this study, by combining metabolomics and genetical, enzymological, biochemical, and molecular approaches, we were able to draw a comprehensive map of the functional roles 14-3-3 proteins play in essential metabolic processes.

Our study further confirms that 14-3-3 proteins are important regulators of both nitrogen and carbon metabolic processes. Specifically, we show that 14-3-3 proteins play roles to control the tricarboxylic acid (TCA) cycle and the shikimate pathway.

\section{Results}

Metabolite profiling: ectopic expression of 14-3-3 proteins altered primary metabolite levels

Our previous studies demonstrated that 14-3-3 chi, kappa and psi proteins interact with more than a hundred proteins and that these interactions regulate the activities of some metabolic enzymes [13]. However, it remained unclear why 14-3-3 proteins interact with so many proteins and what their true targets are in planta. To comprehend the biological roles of 14-3-3 proteins, metabolic profiling was performed on plants overexpressing a 14-3-3 protein (14-3-3 ox) and on previously confirmed 14-3-3 kappa knockout plants (kappa-KO), 14-3-3 chi knockout plants (chi-KO) and 14-3-3 psi RNAi plants (psi-RNAi) that showed 70\% reduction of endogenous 14-3-3 psi expression [13]. 14-3-3 ox plants with 14-3-3 contents of at least two times more than wild type in planta were used [13]. Long day (16 h light/8 h dark) plate-grown plants were divided into shoots and roots, and changes in their levels of primary metabolites relative to wild type plants were determined using GC-TOF-MS (gas chromatography-time of flight-mass spectrometry).

To visualize the metabolomic changes in 14-3-3 ox and $\mathrm{KO}$ plants, principal component analysis (PCA) was conducted using metabolite profile data matrix to plot the samples' distribution. 14-3-3 kappa-ox, chi-ox, and psi-ox were distributed in distinguishable clusters, with kappa-ox having the most significantly different metabolite profile compared to wild type (Figure 1). The subsequent supervised method, orthogonal projections to latent structures-discriminant analysis (OPLS-DA) reconfirmed that 14-3-3 ox plants have different
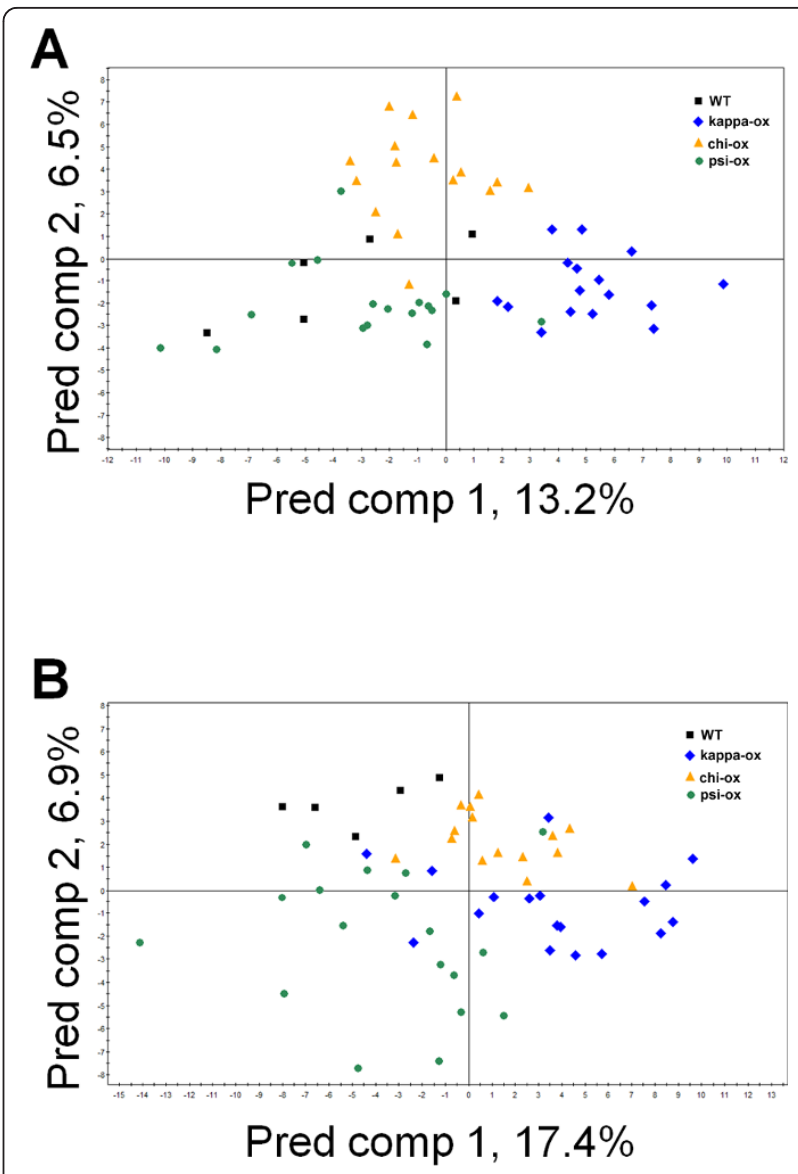

Figure 1 The OPLS-DA score scatter plots of three 14-3-3 overexpressing and wild type samples for (A) shoots and (B) roots. Each point represents an independent plant sample in the score scatter plots. We used 55 shoots and 56 roots for the analysis. (A) The OPLS-DA model for shoot samples shows three significant components, with $R^{2} X, R^{2} Y$ and $Q^{2} Y$ values of $0.37,0.67$ and 0.41 , respectively. (B) The OPLS-DA model for root samples shows three significant components, with $R^{2} X, R^{2} Y$ and $Q^{2} Y$ values of $0.30,0.50$ and 0.23 , respectively. Black square, wild type; blue diamond, kappaox; yellow triangle, chi-ox; green circle, psi-ox.

metabolic profiling patterns compared to wild type (Figure 1). The scatter plot showed that the metabolites, such as amino acids, TCA intermediate and carbohydrates, of 14-3-3 kappa-ox were clearly distinguishable from that of 14-3-3 kappa-KO and wild type (Figure $2 \mathrm{~A})$; and the chi-ox plants showed similar trends of metabolites distribution as 14-3-3 kappa-ox (Figure 2B).

The 14-3-3 ox lines and $\mathrm{KO}$ lines had clear alterations of many metabolites (Table 1 and Additional file 1). Twelve metabolite contents were significantly modified in the roots; and twenty five, in the shoots (Table 1). 14-3-3 chi-ox and 14-3-3 kappa-ox roots had decreased levels of some amino acids, such as alanine, phenylalanine and glutamate, compared to wild type but fewer metabolite changes were found in the roots of 14-3-3 


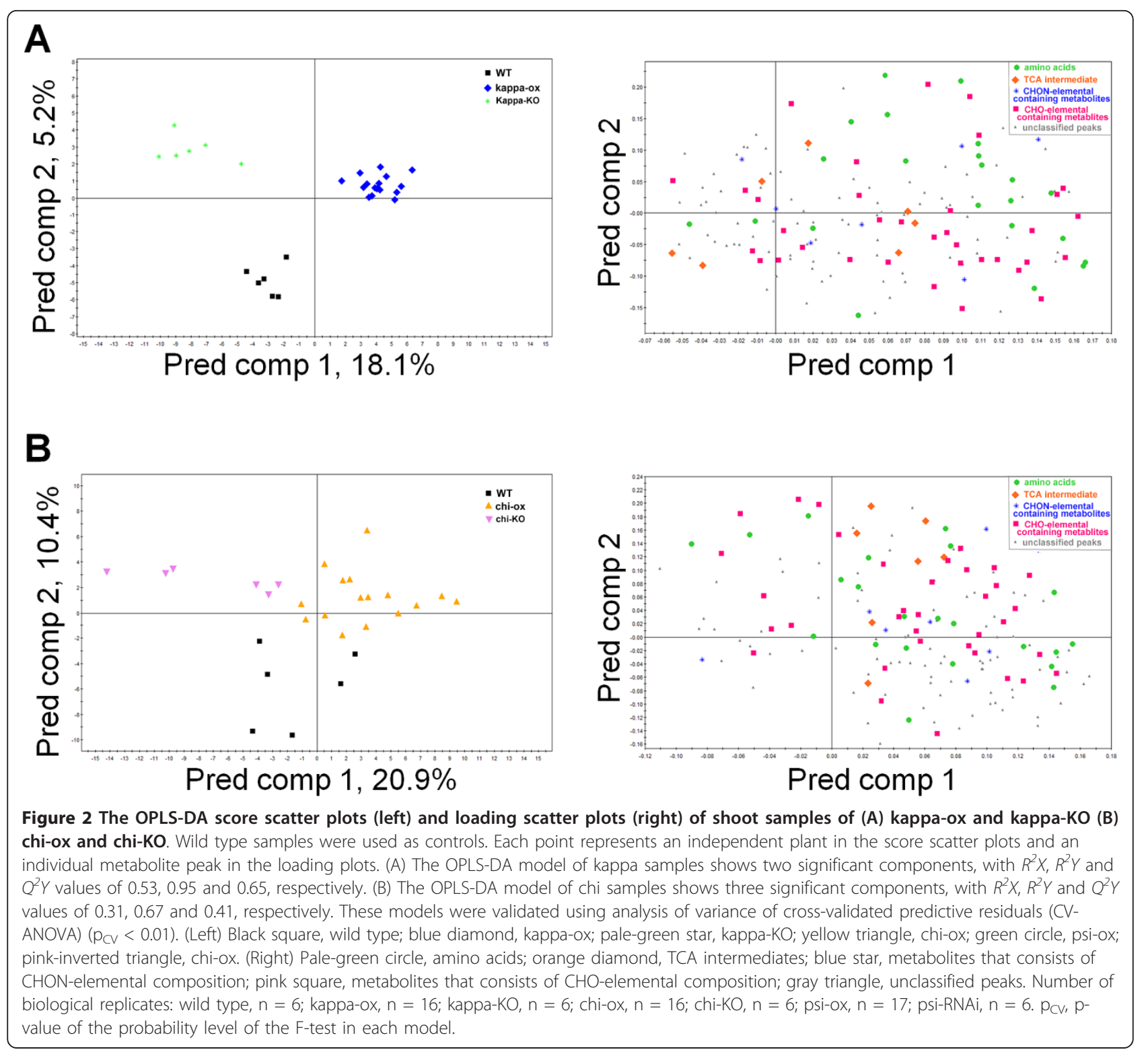

psi-ox and KO plants for all three 14-3-3 proteins. Interestingly, the changes of metabolites in the shoots were more pronounced-the levels of many metabolites that decreased in 14-3-3 ox shoots increased in $\mathrm{KO}$ shoots (Table 1). Metabolites differentially regulated in 14-3-3 ox shoots were divisible into four groups. First, many amino acids, including alanine, glycine, and lysine, decreased in 14-3-3 ox plants. Second, sugar levels decreased in 14-3-3 ox lines. Third, metabolite contents of TCA cycle, such as malate and citrate, decreased in 14-3-3 ox plants. However, levels of $\alpha$-ketoglutarate increased in kappa-ox but decreased in psi-ox. Fourth, metabolites related to the shikimate pathway were altered. The contents of phenylalanine decreased in 143-3 kappa-, chi- and psi- ox lines. In addition, tyrosine amount decreased in kappa ox plants and the contents of shikimate increased in kappa KO plants (Table 1). From these results, it can be hypothesized that 14-3-3 proteins are involved in the regulation of TCA cycle, sugar metabolism and the shikimate pathway.

It has been reported that 14-3-3 proteins and their targets are regulated by light [26,27]. Therefore, comparisons in the levels of metabolites of the 14-3-3 ox lines with that of wild type were made in light and dark conditions (Figure 3). Light and dark did not affect the overall metabolic trends in the 14-3-3 ox plants. However, starch content decrease (with the exception of chiox1 and chi-ox3) was more significant in the dark, at least $12 \%$ more than light; whereas malate content decrease was more significant in the light, at least $10 \%$ 
Table 1 List of signature metabolites that were changed in 14-3-3 overexpression plants compared to wild type plants.

\begin{tabular}{|c|c|c|c|c|c|c|c|c|c|c|c|c|c|}
\hline & \multirow[b]{2}{*}{ Metabolite } & \multicolumn{12}{|c|}{ Fold change compared to wild type plants } \\
\hline & & $\begin{array}{l}\text { kappa- } \\
\text { ox1 }\end{array}$ & $\begin{array}{l}\text { kappa- } \\
\text { ox2 }\end{array}$ & $\begin{array}{l}\text { kappa- } \\
\text { ox3 }\end{array}$ & $\begin{array}{l}\text { kappa- } \\
\text { KO }\end{array}$ & $\begin{array}{l}\text { chi- } \\
\text { ox1 }\end{array}$ & $\begin{array}{l}\text { chi- } \\
\text { ox2 }\end{array}$ & $\begin{array}{l}\text { chi- } \\
\text { ox3 }\end{array}$ & $\begin{array}{l}\text { chi- } \\
\text { KO }\end{array}$ & $\begin{array}{l}\text { psi- } \\
\text { ox1 }\end{array}$ & $\begin{array}{l}\text { psi- } \\
\text { ox2 }\end{array}$ & $\begin{array}{l}\text { psi- } \\
\text { ox3 }\end{array}$ & $\begin{array}{l}\text { psi- } \\
\text { RNAi }\end{array}$ \\
\hline \multirow[t]{25}{*}{ Shoot } & $\beta$-alanine & 0.613 & 0.741 & 0.628 & 1.401 & 0.809 & 0.912 & 1.002 & 1.642 & 1.662 & 1.296 & 0.999 & 2.087 \\
\hline & GABA & 0.682 & 0.527 & 0.440 & 1.271 & 0.627 & 0.886 & 0.647 & 0.836 & 1.101 & 0.571 & 0.578 & 0.758 \\
\hline & threonic acid & 0.616 & 0.657 & 0.641 & 1.178 & 1.106 & 1.324 & 0.859 & 0.945 & 0.973 & 0.662 & 0.869 & 1.524 \\
\hline & phenylalanine & 0.746 & 0.764 & 0.572 & 1.050 & 0.702 & 0.798 & 1.032 & 1.009 & 1.102 & 0.813 & 0.692 & 0.793 \\
\hline & $\begin{array}{l}\text { 1,3-diaminopropane } \\
\text { dihydrochloride }\end{array}$ & 0.546 & 0.496 & 0.413 & 0.875 & 0.439 & 0.485 & 0.478 & 0.711 & 0.761 & 0.574 & 0.473 & 0.552 \\
\hline & ribose & 0.747 & 0.618 & 0.415 & 1.501 & 0.651 & 0.929 & 0.809 & 1.110 & 1.358 & 0.876 & 0.740 & 1.102 \\
\hline & citrate & 0.825 & 0.735 & 0.733 & 1.154 & 0.444 & 0.654 & 0.538 & 0.799 & 1.222 & 0.595 & 0.670 & 0.712 \\
\hline & fructose & 0.439 & 0.447 & 0.479 & 0.771 & 0.335 & 0.419 & 0.426 & 0.904 & 0.670 & 0.500 & 0.461 & 0.914 \\
\hline & tyrosine & 0.639 & 0.684 & 0.323 & 0.681 & 1.013 & 1.107 & 1.082 & 0.991 & 1.687 & 1.036 & 0.969 & 1.130 \\
\hline & glycine & 0.448 & 0.402 & 0.364 & 0.984 & 0.517 & 0.485 & 0.722 & 0.786 & 1.384 & 0.935 & 0.640 & 0.704 \\
\hline & aspartate & 0.860 & 0.707 & 0.648 & 1.936 & 0.764 & 1.115 & 1.068 & 1.535 & 1.258 & 1.027 & 0.926 & 1.181 \\
\hline & pyroglutamate & 0.855 & 0.833 & 0.590 & 1.709 & 0.775 & 1.008 & 1.041 & 1.444 & 1.051 & 0.873 & 0.758 & 0.869 \\
\hline & glutamate & 0.921 & 1.044 & 0.766 & 1.734 & 0.850 & 1.089 & 0.934 & 1.375 & 1.132 & 1.046 & 0.935 & 1.083 \\
\hline & asparagine & 0.922 & 0.561 & 0.350 & 2.059 & 0.762 & 1.338 & 0.979 & 1.393 & 1.351 & 0.917 & 0.710 & 1.363 \\
\hline & glutamine & 0.697 & 0.439 & 0.214 & 0.858 & 0.696 & 0.986 & 0.703 & 0.578 & 1.484 & 1.213 & 0.743 & 1.283 \\
\hline & glucose & 0.451 & 0.387 & 0.278 & 0.723 & 0.294 & 0.335 & 0.336 & 0.530 & 0.567 & 0.475 & 0.360 & 0.720 \\
\hline & lysine & 0.892 & 0.687 & 0.374 & 1.052 & 0.919 & 1.207 & 1.041 & 1.069 & 1.069 & 0.908 & 0.729 & 1.016 \\
\hline & sucrose & 0.550 & 0.454 & 0.354 & 0.647 & 0.489 & 0.721 & 0.603 & 0.820 & 0.501 & 0.550 & 0.251 & 0.681 \\
\hline & palmitate & 0.813 & 1.013 & 0.984 & 1.193 & 0.878 & 0.922 & 1.069 & 1.231 & 0.986 & 0.919 & 0.804 & 0.904 \\
\hline & shikimate & 0.846 & 0.722 & 0.602 & 1.801 & 0.788 & 0.776 & 0.678 & 1.322 & 1.073 & 0.965 & 0.718 & 0.950 \\
\hline & 1,4-diaminobutane & 0.609 & 0.561 & 0.484 & 0.953 & 1.333 & 1.522 & 0.986 & 0.973 & 0.912 & 0.775 & 0.917 & 1.758 \\
\hline & Fructose-6-phosphate & 1.156 & 0.800 & 0.678 & 1.655 & 0.642 & 0.879 & 0.942 & 1.108 & 1.089 & 0.967 & 0.771 & 1.071 \\
\hline & malate & 0.745 & 0.665 & 0.642 & 1.017 & 0.674 & 0.866 & 0.809 & 0.847 & 1.452 & 0.911 & 0.955 & 1.008 \\
\hline & $\alpha$-ketoglutarate & 0.566 & 0.991 & 0.546 & 0.653 & 0.465 & 0.701 & 0.657 & 0.583 & 3.061 & 1.869 & 2.120 & 1.111 \\
\hline & myo-inositol & 0.746 & 0.969 & 0.562 & 1.487 & 1.251 & 1.039 & 0.805 & 1.275 & 0.971 & 0.933 & 0.865 & 1.181 \\
\hline \multirow[t]{12}{*}{ Root } & $\beta$-alanine & 0.662 & 0.830 & 0.647 & 1.331 & 0.649 & 0.617 & 0.703 & 0.891 & 1.009 & 0.621 & 0.749 & 1.153 \\
\hline & phenylalanine & 0.739 & 0.742 & 0.509 & 1.314 & 0.697 & 0.792 & 0.842 & 1.158 & 0.964 & 0.849 & 0.722 & 0.880 \\
\hline & proline & 2.282 & 1.578 & 0.762 & 1.301 & 2.046 & 1.700 & 1.254 & 1.908 & 2.318 & 1.678 & 3.929 & 2.340 \\
\hline & pyroglutamate & 0.755 & 0.734 & 0.525 & 1.341 & 0.751 & 0.836 & 0.852 & 1.250 & 0.923 & 0.775 & 0.529 & 0.801 \\
\hline & glutamate & 0.685 & 0.875 & 0.546 & 1.237 & 0.741 & 0.766 & 0.788 & 1.077 & 1.055 & 0.815 & 0.762 & 0.964 \\
\hline & trans-Sinapate & 0.447 & 0.751 & 0.409 & 0.697 & 0.616 & 0.553 & 0.516 & 0.567 & 0.643 & 0.690 & 0.470 & 0.723 \\
\hline & palmitate & 0.742 & 0.945 & 0.814 & 1.103 & 0.800 & 0.784 & 0.864 & 1.060 & 0.992 & 0.912 & 0.723 & 0.845 \\
\hline & 1,4-diaminobutane & 0.960 & 0.935 & 0.767 & 1.645 & 0.635 & 0.736 & 0.857 & 0.985 & 1.112 & 0.794 & 0.933 & 1.209 \\
\hline & Fructose-6-phosphate & 0.780 & 0.751 & 0.538 & 1.251 & 0.780 & 0.860 & 0.790 & 1.059 & 0.906 & 0.779 & 0.598 & 0.908 \\
\hline & shikimate & 1.946 & 1.912 & 1.702 & 3.127 & 1.553 & 1.666 & 1.811 & 1.979 & 2.161 & 1.733 & 1.909 & 2.311 \\
\hline & myo-inositol & 0.716 & 0.806 & 0.626 & 1.385 & 0.909 & 0.763 & 0.821 & 1.249 & 0.980 & 0.867 & 0.699 & 1.043 \\
\hline & phytol & 0.179 & 0.438 & 0.141 & 1.137 & 0.233 & 0.154 & 0.219 & 1.089 & 0.374 & 0.418 & 0.167 & 0.266 \\
\hline
\end{tabular}

Bold letter indicates statistically significant in metabolite level in the line compared to wild type $(P<0.05)$.

more than dark. The alteration of metabolite levels in 14-3-3-ox plants was therefore independent of the presence or absence of light. This indicates that the targets of the 14-3-3 proteins do not act in an exclusively lightdependent manner.
Activity levels of primary metabolic enzymes in 14-3-3 ox plants

The metabolite profile of 14-3-3 ox plants suggests that starch and sugar metabolism, TCA cycle, and the shikimate pathway are the main target processes of 14-3-3 


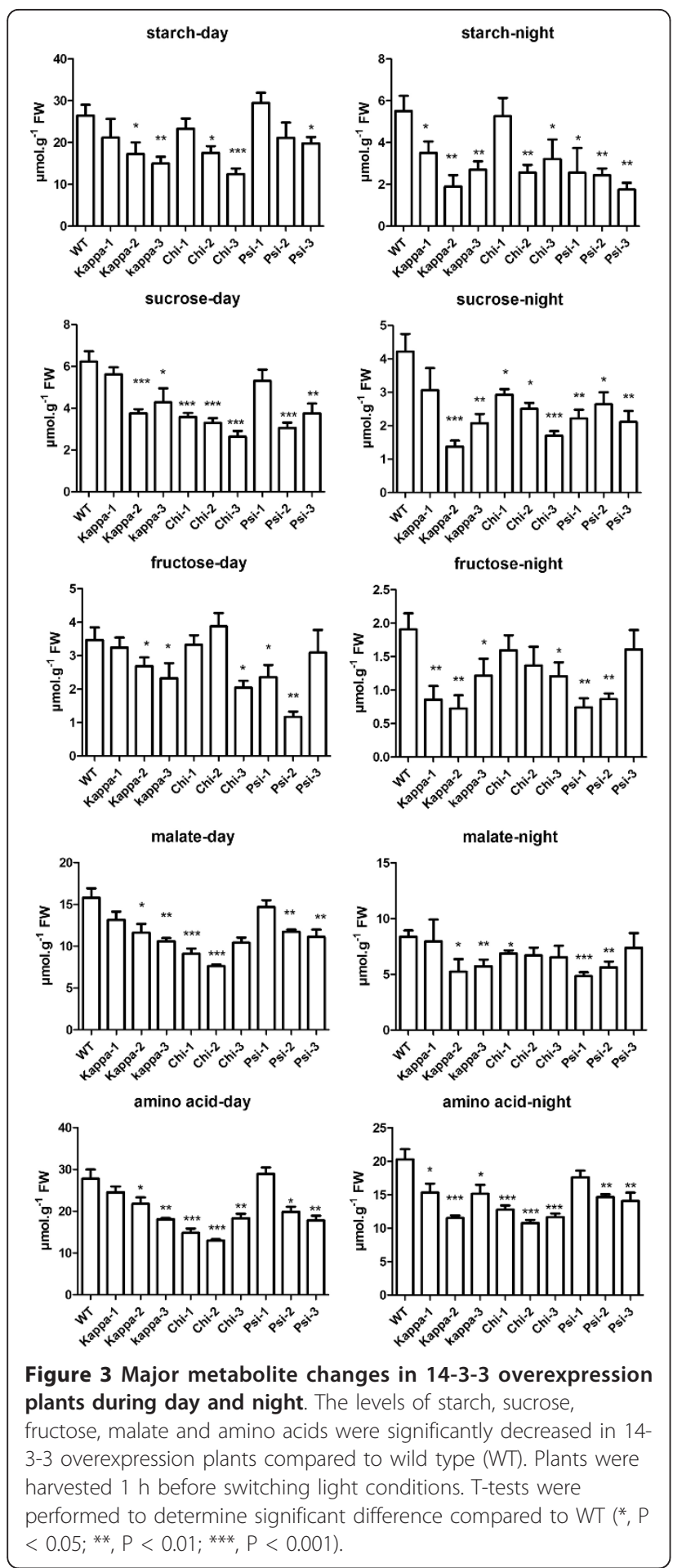

proteins. To elucidate whether the enzymes of these metabolic processes are regulated by 14-3-3 proteins, the activity of 29 enzymes in 14-3-3 ox plants and wild type plants were analyzed (Figure 4 and Additional file 2 ). Because the most marked metabolic changes were
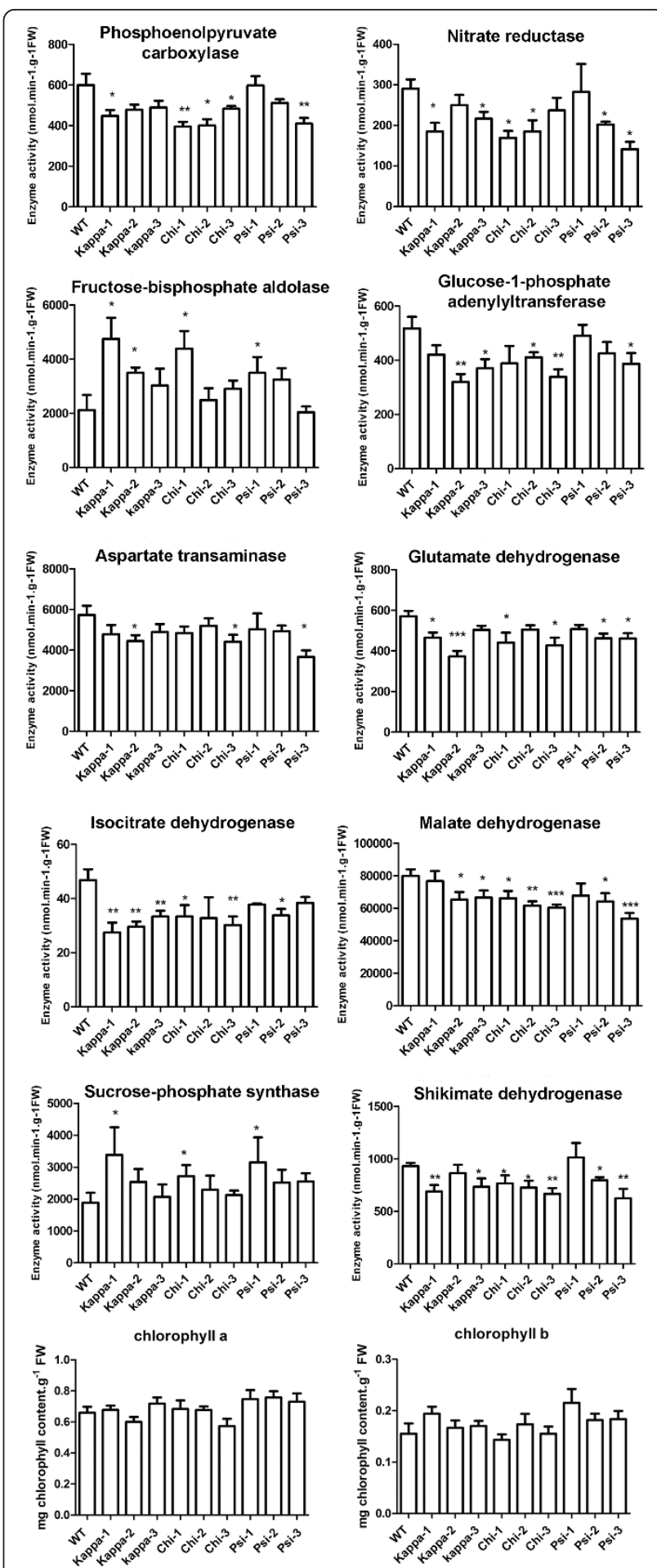

Figure 4 The activities of metabolic enzymes were altered in 14-3-3 overexpression plants. Enzyme activities were determined in 14-3-3 overexpression plants and wild type Col-0 plants (WT). Asterisks indicate significant differences compared to WT as determined by t-test with $\mathrm{n}>7$ ( $^{*}, \mathrm{P}<0.05$; ${ }^{* *}, \mathrm{P}<0.01$; ***, $\mathrm{P}<$ 0.001). 
found in the shoots (Table 1), only shoots were used for determining the enzyme activities.

We consider that there was no general reformatting of photosynthesis in 14-3-3 ox plants basing on the fact that: 1) the chlorophyll content in 14-3-3 ox plants and wild type plants were not significantly different (Figure $4)$; 2) the activities of 19 enzymes, including phosphoglucomutase, UDP glucopyrophosphorylase, the sucrose metabolizing enzymes glucokinase, fructokinase and $\beta$ fructofuranosidase, and the Calvin-Benson cycle enzymes triose phosphate isomerase, glyceraldehyde-3phosphate dehydrogenase and RubisCO were not altered in the 14-3-3 ox plants (Additional file 2).

As already known from other studies $[15,17,18,28]$, the activity of nitrate reductase decreased and the activity of sucrose phosphate synthase increased in 14-3-3 ox plants (Figure 4). Our previous findings showing that the activity of phosphoenol pyruvate carboxylase decrease and that the activity of glutamate synthase does not change in 14-3-3 ox plants [13] were confirmed in this study (Figure 4). Interestingly, several enzymes involved in TCA cycle (malate dehydrogenase and isocitrate dehydrogenase), or closely related to TCA cycle (glutamate dehydrogenase and aspartate aminotransferase) displayed decreased activities in 14-3-3 ox plants (Figure 4). The activity of citrate synthase also decreased in some of the 14-3-3 ox lines (Additional file 2). In addition to enzymes of TCA cycle, fructose bisphosphate aldolase activity increased in 14-3-3 ox plants compared to wild type plants. The decreased activity of glucose-1-phosphate adenylytransferse (Figure 4), which is involved in starch synthesis, may be responsible for the decreased starch synthesis observed in 14-3-3 ox lines (Figure 3).
14-3-3 proteins function in the shikimate pathway Shikimate levels significantly increased in kappa-KO compared with wild type plants (Table 1). In addition, the enzyme activity of shikimate dehydrogenase was significantly reduced in 14-3-3 ox plants (Figure 4). Because shikimate dehydrogenase is essential for the biosynthesis of aromatic compounds in plants [29], this result is in accordance with the reduced levels of phenylalanine in the chi, kappa, and psi ox lines, of tyrosine in the kappa-ox lines, and of phytol in the 14-3-3 ox roots (Table 1). Together, these results suggest that 14-3-3 proteins play important roles in the regulation of the shikimate pathway.

TCA cycle regulated by $14-3-3$ proteins through proteinprotein interaction

The metabolomic profiling (Table 1 and Figure 3 ) and the analysis of enzyme activities in 14-3-3 ox and wild type plants (Figure 4) suggest that TCA cycle is regulated by 14-3-3 proteins. Our previous list of proteins found to interact with 14-3-3 proteins [13] includes two malate dehydrogenases (At1G04410 and At5G43330), an isocitrate dehydrogenase (At4G35650), and also an aspartate aminotransferase (At2G30970), which altered activities in 14-3-3 ox plants. To confirm whether these TCA cycle enzymes are direct targets of 14-3-3 proteins, yeast two-hybrid interaction assays were performed (Figure 5). The malate dehydrogenases and isocitrate dehydrogenase clearly interacted with 14-3-3 kappa, chi, and psi in yeast (Figure 5), suggesting that 14-3-3 proteins control TCA cycle through interaction with its metabolic enzymes, malate dehydrogenase and isocitrate dehydrogenase (Figure 6).

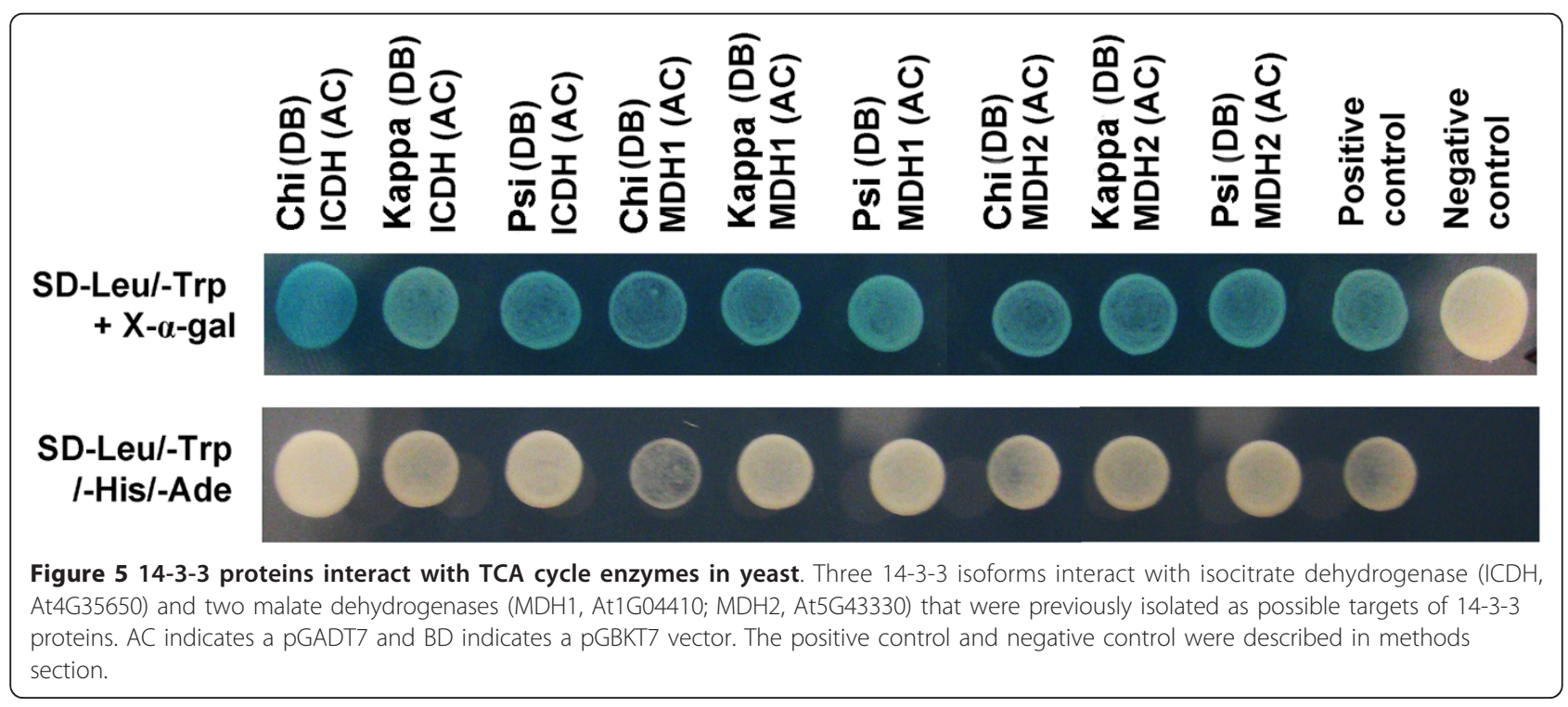




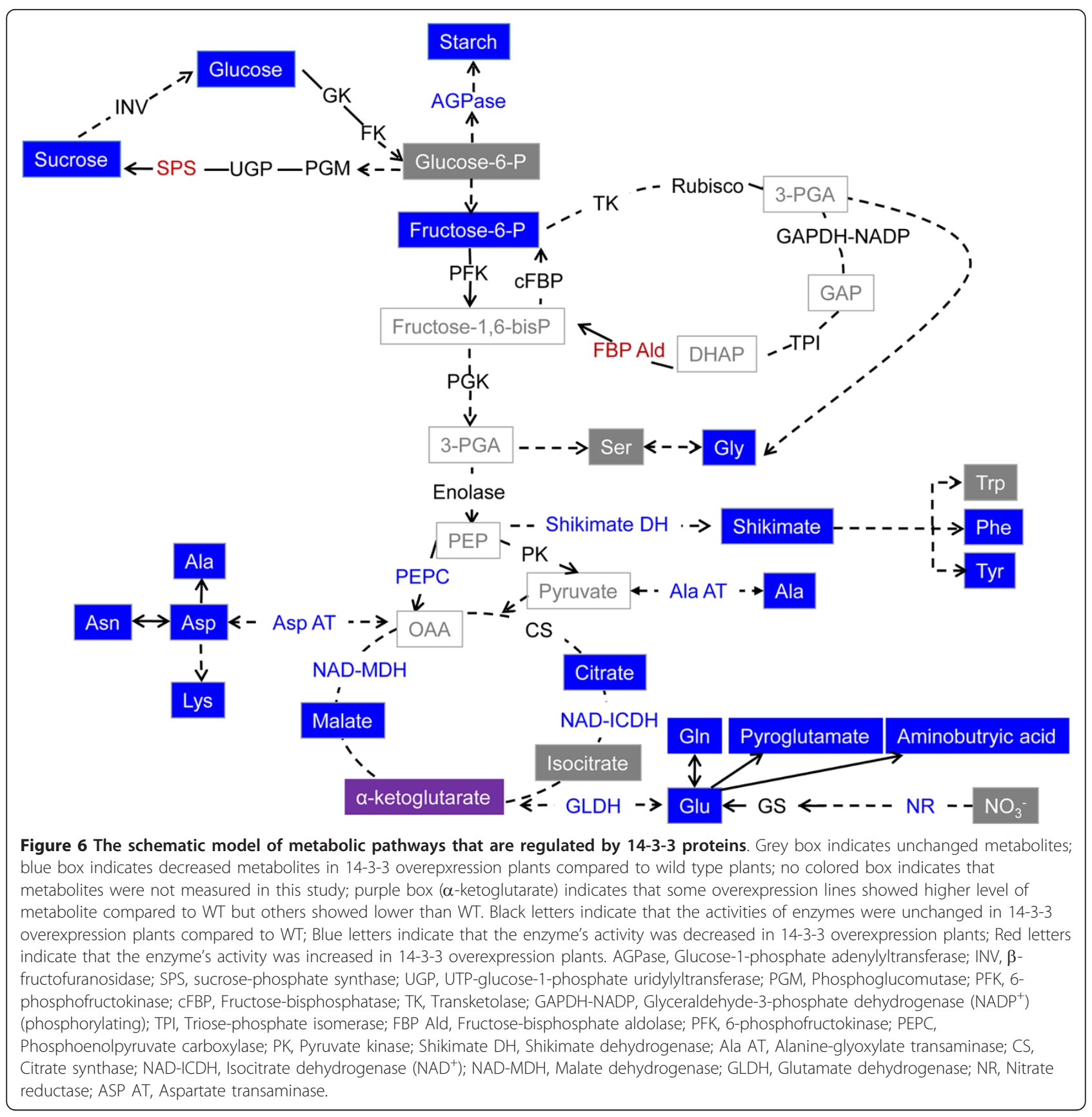

\section{Discussion}

Numerous studies have shown that there are more than a hundred potential 14-3-3 target proteins in plants [3-5,30-34]. In vivo, the cellular distribution of 14-3-3 proteins are altered depending on the interactions with cellular clients [35]. There are numerous examples of 14-3-3 proteins interacting with and regulating various target proteins in different subcellular compartments including cytosol, nucleus, chloroplast as well as mitochondria [36-40]. These results suggest that 14-3-3 proteins localize in various subcellular compartments and play diverse roles in many cellular processes. To better understand the multi-faceted roles of 14-3-3 proteins in planta, a combination of metabolomics, enzyme activity analysis, and protein-protein interaction analysis was used in this study.

The interaction between nitrate reductase and 14-3-3 proteins was demonstrated in various plant species using multiple methods $[15,16]$. However, the decrease in nitrate reductase activity upon interaction with 14-33 proteins has only been measured in vitro, and the direct influence of 14-3-3 proteins on nitrogen 
metabolite levels in planta has not been clearly reported [16]. Through metabolomics, we found decreased levels of nitrogen containing metabolites, such as glycine, GABA, glutamine and asparagine (Table 1) possibly resulting from the alteration of nitrogen metabolic enzymes by 14-3-3 proteins (Figure 4) [41,42].

In addition to the regulation of nitrate reductase, 143-3 proteins control nitrogen metabolism through interaction with glutamine synthetase (GS) enzyme [8]. In Medicago truncatula, degradation of GS2 by proteolysis was related to the binding of 14-3-3 proteins to phosphorylated GS2 [43]. In contrast, in Brassica napus, 143-3 proteins were shown to positively regulate activity and to negatively regulate degradation of the cytosolic isoform of GS1 [38,43]. In healthy plants, the plastidlocalized GS2 isoform is predominant compared to GS1 isoform. However, during senescence, GS2 degrades with the chloroplast and GS1 becomes the predominant isoform in leaves [44]. In this study, as well as in the previous study using 14-3-3 ox lines ([13]), no significant changes of GS activities were detected (Additional file 2). There are several possible explanations for the unchanged activity of GS in our conditions: 1) the change of GS activity in 14-3-3 ox plants was not great enough to be detected by our method; 2) the amount of GS proteins in 14-3-3 ox plants was a limiting factor and/or there was enough 14-3-3 protein in wild type plants to saturate GS activity; 3) alterations of metabolites related to nitrogen metabolism were not due to an alteration of GS activity but a disruption of the carbonnitrogen balance, since drastic changes in soluble sugar and starch levels were observed in 14-3-3 ox lines (Table 1) [45-47]; 4) the method used to measure total GS activity in this study was unable to discriminate GS1 and GS2, or distinguish whether the balance between GS1 and GS2 had been modified in the 14-3-3 ox plants.

As photoperiodism is associated with drastic gene expressions, enzyme activities and metabolite level changes, samples were analyzed at time points most representative of these two periods: one hour before onset of dark when plants have accumulated maximum photosynthate such as starch, and one hour before onset of light when they have remobilized photosynthate to ensure normal growth and development. Since metabolic profiles at these two time points did not change overall metabolic trend, we can exclude photoperiodism as a factor affecting the reduction of carbohydrates in 14-3-3 ox plants.

The reduction of starch, sucrose and glucose levels in 14-3-3 ox plants (Table 1 and Figure 3) indicates that 14-3-3 proteins regulate activities of enzymes related to carbohydrate metabolism. 14-3-3 proteins bind to several enzymes of carbohydrate metabolism, such as sucrose phosphate synthase, trehalose-6-phosphate synthase and 6-phosphofructo-2-kinase/fructose-2,6bisphosphatase $[19,20,48]$. Our results suggest that overexpression of 14-3-3 proteins in planta is associated with the modification of these carbohydrate metabolic enzymes and the decrease of sucrose and starch levels in leaves. In addition, sucrose phosphate synthase has several putative phosphorylation sites which regulate its activities by interacting with $14-3-3$ proteins $[8,19]$. Although effect by other levels of regulation such as feedback control cannot be ignored, we hypothesize that change in soluble sugar levels in 14-3-3 ox plants resulted from the regulation of carbohydrate metabolic enzymes by 14-3-3 proteins and the lower fluxes in TCA cycle.

In this study, detailed metabolomics analysis clearly show that overexpression of 14-3-3 proteins is associated with drastic changes in the levels of TCA-intermediates (Table 1). The modifications in the levels of these TCA cycle intermediates coincide with decreased malate dehydrogenase and isocitrate dehydrogenase activities (Figure 4). Moreover, we found that malate dehydrogenase and isocitrate dehydrogenase are interacting partners of 14-3-3 chi, kappa, and psi (Figure 5), with putative 14-3-3 binding motifs. Another study identified a different form of isocitrate dehydrogenase isoform as a possible interacting partner of 14-3-3 proteins [49]. The modifications of metabolites involved in TCA cycle by 14-3-3s were due to alterations in the activities of several TCA metabolic enzymes. It is highly likely that the interactions of 14-3-3 proteins and two TCA key enzymes, malate dehydrogenase and isocitrate dehydrogenase, are the crucial factor controlling these enzyme activities. Considering these results, we conclude that 14-3-3 proteins regulate TCA cycle through protein-protein interaction with several enzymes of TCA cycle.

In addition to TCA cycle, our findings show that overexpression of 14-3-3 proteins deregulate the shikimate pathway, which plays a pivotal role in the production of precursors for aromatic compounds including aromatic amino acids in plants [50]. The activity of shikimate dehydrogenase was down-regulated in 14-3-3 ox lines (Figure 4), and the shikimate level was higher in 14-3-3 kappa-KO plants (Table 1). The decrease of tyrosine and phenylalanine in 14-3-3 ox plants (Table 1) also supports the notion that $14-3-3$ proteins affect the shikimate pathway.

Plant metabolic processes are complicate, delicate and tightly linked reciprocally. Plants therefore need multifunctional players that can modulate multiple processes as well as the steps in each process and 14-3-3 proteins are one of the best candidates for this role. 14-3-3 proteins reversibly interact with selectively phosphorylated 
form of proteins and are involved in affecting targets to function in multiple ways such as confirmation change, scaffolding, and altering cellular location [2]. This is why 14-3-3 proteins have hundreds of target proteins and their interactions are found ubiquitously. In this study, we took established individual metabolic processes such as nitrogen metabolism, and aimed to uncover the ubiquitous roles 14-3-3 proteins play in the tightly linked metabolic processes. In 14-3-3 ox plants, reduction of starch levels may be due to decreased activity of Glucose-1-phosphate adenylyltransferase (AGPase). AGPase catalyzes the synthesis of ADP-Glc, the glucosyl donor used by starch synthases for starch biosynthesis [51], and regulates carbon storage in Arabidopsis [52]. AGPase is subjected to transcriptional regulation in diverse tissues and additional regulatory mechanisms at the posttranscriptional level [53]. The activities of starch metabolic enzymes are modulated by effector molecules which are often metabolic intermediates, or by posttranslational protein modification like phosphorylation [52]. Recent studies implicate that reversible protein phosphorylation play a critical role in the regulation of starch related enzymes such as AGPase $[54,55]$. Phosphorylated AGPase is possibly a target of 14-3-3 proteins and the binding can be a way to control its activity. From our study, we conclude that modification of AGPase activity is caused by drastic changes of carbon compounds in the 14-3-3 ox plants and the binding of 14-3-3 proteins with the phosphorylated form of the AGPase. As a consequence, 14-3-3 ox plants have greatly reduced levels of key metabolites in glycolysis leading to the decrease in carbohydrate supply to TCA cycle and shikimate pathway. Assimilation of ammonium to glutamine and glutamate is also negatively regulated in 14-3-3 ox plants, also suppressing supply to TCA cycle (Figure 6). In our study, we revealed that malate dehydrogenase and isocitrate dehydrogenase are direct targets of 14-3-3 proteins (Figure $5)$. This result suggests a mechanism in which 14-3-3 proteins bind and regulate key enzymes of TCA cycle through altering conformational change or scaffolding via protein-protein interaction. In addition, the decrease of glutamine and glutamate content due to ubiquitous interaction with 14-3-3 proteins and nitrate reductase and GS limit input to TCA cycle (Figure 6). With these results, we theorize that the ubiquitous interactions between 14-3-3 proteins and multiple metabolic enzymes restrict input to TCA cycle and shikimate pathway and consequently, TCA cycle itself is modulated by 14-3-3 protein via protein-protein interaction.

\section{Conclusions}

Integration of metabolome data with a panel of enzyme assays proved to be a powerful tool to further our understanding of the function of 14-3-3 proteins in the regulation of primary metabolism in Arabidopsis. We confirmed that 14-3-3 proteins modulate activities of key enzymes of carbon and nitrogen metabolism and that these modifications were associated with drastic changes in the carbon/nitrogen balance in plants. In this study, we provide a novel functional link between 14-33 proteins and TCA cycle. The modification of the multiple metabolites involved in TCA cycle may have occurred due to the modification of enzyme activities of TCA cycle. Furthermore, our findings suggest that 14-33 proteins regulate TCA cycle through their interactions with two key enzymes of TCA cycle and that 14-3-3 proteins regulate the shikimate pathway and thus the production of aromatic compounds.

\section{Methods}

\section{Plant materials and growth condition}

Plants were grown on low salt media (LSM; $1.25 \mathrm{mM}$ $\mathrm{KNO}_{3}, 2 \mathrm{mM} \mathrm{Ca}\left(\mathrm{NO}_{3}\right)_{2}, 0.75 \mathrm{mM} \mathrm{MgSO} 4,0.5 \mathrm{mM}$ $\mathrm{KH}_{2} \mathrm{PO}_{4}, 50 \mu \mathrm{M} \mathrm{H}_{3} \mathrm{BO}_{3}, 10 \mu \mathrm{M} \mathrm{MnCl}, 2 \mu \mathrm{M} \mathrm{ZnSO}$, $1.5 \mu \mathrm{M} \mathrm{CuSO}_{4}, 0.075 \mu \mathrm{M} \mathrm{NH} \mathrm{No}_{7} \mathrm{O}_{24}, 74 \mu \mathrm{M} \mathrm{Fe}-$ EDTA, pH 5.7) with $1 \%$ sucrose and $0.6 \%$ Seakem agarose at $22^{\circ} \mathrm{C}$ with $16 \mathrm{~h}$ daylight at $150 \mu \mathrm{mol} \mathrm{m} \mathrm{m}^{-2} \mathrm{~s}^{-1}$ [56]. The all Arabidopsis plants used in this study have the same ecotype background, Col-0. Plants overexpressing 14-3-3 kappa, 14-3-3 chi and 14-3-3 psi and the knockout mutants of 14-3-3 genes were used as described [13]. For metabolomic profiling and enzyme activity analysis, three days after germination, plants were transferred onto new LSM plates and grown vertically. To reduce the effect by the position of plates in the growth chamber, plates were moved every two days. After two weeks, shoots and roots were harvested separately.

\section{Metabolite profiling and statistical analysis}

Metabolite profiling using GC-TOF-MS was performed as described in [57]. Briefly, three of the harvested shoot or root samples were pooled as a replicate. Six replicates per line were used for metabolite profiling. A total of 5 mg fresh weight of the shoot and root samples were subjected to derivatization. An equivalent $6 \mu \mathrm{g}$ of the derivatized samples were injected into the GC-MS instrument. The non-processed data obtained were preprocessed using the hierarchical multivariate curve resolution method [58].

SIMCA-P +12 software (Umetrics, Umeå, Sweden) were used for multivariate statistical analyses (i.e., PCA and OPLS-DA) and the R statistical environment http:// cran.r-project.org for other statistical analyses such as the cross-contribution compensating multiple standard normalization (CCMN) and calculation of a false discovery rate (FDR). The PCA and OPLS-DA models were used to visualize the high-dimensional data and 
determine the metabolomic variation between the control (wild type) and the mutants (ox and/or KO). PCA was carried out to show how different variables (metabolites) change in relation to each other. OPLS-DA, which is as an extension of the supervised multivariate regression method PLS, was employed to remove some variation which was uncorrelated to class separation.

Outliers in the GC-MS data were identified using missing value robust PCA [59] and removed prior to further analysis. Metabolite abundance estimates were log transformed and scaled to unit-variance where applicable. Analytical bias was monitored via 11 internal, isotope-labeled standards and removed using the CCMN [60]. To validate OPLS-DA models, we applied analysis of variance of cross-validated predictive residuals (CVANOVA) in the SIMCA-P software [61].

Differentially abundant metabolites were identified using the LIMMA package [62]. Briefly, a linear model was fitted to each metabolite to compare the levels of wild type with levels in the mutants. Significant changes were declared for metabolites with a FDR level $<0.05$ [63].

The day and night change of metabolites were analyzed as described $[64,65]$. Three of the harvested shoots were pooled as a replicate and six to eight replicates per genotype were analyzed. For day condition, long-daygrown (16 h light/ $8 \mathrm{~h}$ dark) plants were harvested 1 hour before offset of light and for night condition the plants were harvested 1 hour before onset of light. All data sets were analyzed for statistical differences compared to wild type by t-test using Prism 5 program (GraphicPad software, La Jolla, USA).

\section{Enzyme and metabolite assays}

Chemicals were purchased as described in [66]. Fifteen of the harvested shoots were pooled as a replicate and six to eight replicates per genotype were analyzed. For enzyme measurements, aliquots of $20 \mathrm{mg}$ frozen $\mathrm{FW}$ were extracted by vigorous mixing with extraction buffer [65]. 6-phosphofructokinase, citrate synthase, isocitrate dehydrogenase, and malate dehydrogenase were assayed as described in [65]. Ribulose-bisphosphate carboxylase was assayed as described in [67]. Triose-phosphate isomerase was assayed as described in [68]. Phosphoglucomutase was assayed as described in [69]. UTP-glucose-1-phosphate uridylyltransferase was assayed as described [70]. Fructosebisphosphate aldolase was assayed by incubating crude extract or dihydroxyacetone phosphate standards for 20 min in a freshly prepared medium containing 0 or $5 \mathrm{mM}$ fructose-1,6-Bisphosphate, $1 \mathrm{U} \mathrm{ml}^{-1}$ triose-P isomerase, 2 $\mathrm{U} \mathrm{ml}^{-1}$ glycerol-3P dehydrogenase, $0.3 \mathrm{mM} \mathrm{NAD}^{+}, 5 \mathrm{mM}$ $\mathrm{MgCl}_{2}, 1 \mathrm{mM}$ EDTA, $0.05 \%$ Triton X 100, and $100 \mathrm{~mm}$ tricine buffer, $\mathrm{pH}$ 8.5. The reaction was stopped by addition of an equal volume of $0.5 \mathrm{M} \mathrm{HCl}$. After incubation for 10 min at RT and neutralization with $0.5 \mathrm{M} \mathrm{NaOH}$, the glycerol-3-phosphate produced was determined using the glycerol-3-phosphate/dihydroxyacetone phosphatebased cycling protocol described in [66]. All other enzymes assays in this study were performed as described in [66]. The statistical differences between each genotype and wild type were analyzed by $\mathrm{t}$-test.

\section{Protein-protein interaction assays}

The interaction between three 14-3-3 isoforms (14-3-3 chi, At4G09000; 14-3-3 kappa, At5G65430; 14-3-3 psi, At5G38480), and two malate dehydrogenases (At1G04410 and At5G43330) and an isocitrate dehydrogenase (At4G35650) were confirmed using GAL4-based Matchmaker yeast two-hybrid system (Clontech). Target proteins were cloned into pGADT7 (Clontech) with the GATEWAY cassette (Invitrogen) and then transformed into yeast strain AH109 using the lithium acetatemediated method. The 14-3-3 proteins were cloned into pGBKT7 with the GATEWAY cassette (Invitrogen) and then transformed into Y187 and were confirmed that there were no autocatalytic activities. GFP and empty vectors were used as a negative control for protein-protein interaction [71]. Skip19 (At4G05460) and ASK2 (At5G42190) were used as a positive control for protein-protein interaction [72]. Yeast transformation and protein-protein interaction assays on selective media (Synthetic Dropout (SD)-Leu/-Trp/-His/-Ade and SDLeu/-Trp $+\mathrm{X}-\alpha-$ gal) were performed according to the manufacturer's instructions.

\section{Additional material}

Additional file 1: Changes in metabolite profiles.

Additional file 2: The list of enzymes that were measured in this study. Enzyme activities were determined in 14-3-3 overexpression plants and wild type Col-0 plants (WT). The asterisk indicates significantly different compared to $W T$ as determined by t-test (*, $P<0.05, n>7)$.

\section{Abbreviations}

14-3-3 ox: 14-3-3 overexpression line; chi-KO: 14-3-3 chi knockout line; GCTOF-MS: gas chromatography-time of flight-mass spectrometry; GS: glutamine synthetase; kappa-KO: 14-3-3 kappa knockout line; PCA: principal component analysis Pred comp: predictive component; psi-RNAi: 14-3-3 psi RNAi line; TCA cycle: tricarboxylic acid cycle.

\section{Acknowledgements}

Dr. Naoki Takahashi (RIKEN Plant Science Center) kindly provided the modified yeast two-hybrid vectors and controls. We are indebted to Beatrice Encke and Nicole Krohn (Max Planck Institute) and Makoto Kobayashi (RIKEN Plant Science Center) for the technical assistances. Dr. Atsushi Fukushima (RIKEN Plant Science Center) gave us statistical advice for multivariate analysis. This work was supported by funds from a RIKEN President's Discretionary Fund (Shin, R.) and the Max Planck Society (Sulpice, R \& Stitt, M).

\section{Author details}

${ }^{1}$ RIKEN Plant Science Center, Yokohama, Kanagawa 230-0045, Japan. ${ }^{2}$ Max Planck Institute for Molecular Plant Physiology, Potsdam-Gölm, 14476, Germany. 


\section{Authors' contributions}

All authors read and approved the final manuscript. CD and RS designed research; $C D, M K, R S, A M, H R$ and RS performed research; $C D, K S, M S$ and RS analyzed data; $C D$ and RS wrote the paper.

Received: 4 August 2011 Accepted: 21 November 2011

Published: 21 November 2011

\section{References}

1. Aitken A: 14-3-3 proteins: A historic overview. Semin Cancer Biol 2006, 16:162-172.

2. Chevalier D, Morris ER, Walker JC: 14-3-3 and FHA domains mediate phosphoprotein interactions. Annu Rev Plant Biol 2009, 60:67-91.

3. Cotelle V, Mackintosh C: Do 14-3-3s regulate 'resource allocation in crops'? Ann Appl Biol 2001, 138:1-7.

4. Ferl RJ, Chung HJ, Sehnke PC: The 14-3-3 proteins: cellular regulators of plant metabolism. Trends Plant Sci 1999, 4:463-463.

5. Oecking C, Jaspert N: Plant 14-3-3 proteins catch up with their mammalian orthologs. Curr Opin Plant Biol 2009, 12:760-765.

6. Kinoshita $T$, Shimazaki $\mathrm{K}$ : Blue light activates the plasma membrane $\mathrm{H}$ ${ }^{+}$-ATPase by phosphorylation of the C-terminus in stomatal guard cells. Embo J 1999, 18:5548-5558.

7. Maudoux O, Batoko H, Oecking C, Gevaert K, Vandekerckhove J, Boutry M, Morsomme P: A plant plasma membrane $\mathrm{H}^{+}$-ATPase expressed in yeast is activated by phosphorylation at its penultimate residue and binding of 14-3-3 regulatory proteins in the absence of fusicoccin. J Biol Chem 2000, 275:17762-17770

8. Moorhead G, Douglas P, Cotelle V, Harthill J, Morrice N, Meek S, Deiting U, Stitt M, Scarabel M, Aitken A, et al: Phosphorylation-dependent interactions between enzymes of plant metabolism and 14-3-3 proteins. Plant J 1999, 18:1-12.

9. Ryu H, Kim K, Cho H, Park J, Choe S, Hwang I: Nucleocytoplasmic shuttling of BZR1 mediated by phosphorylation is essential in Arabidopsis brassinosteroid signaling. Plant Cell 2007, 19:2749-2762.

10. Sottocornola B, Gazzarrini S, Olivari C, Romani G, Valbuzzi P, Thiel G, Moroni A: 14-3-3 proteins regulate the potassium channel KAT1 by dual modes. Plant Biol 2008, 10:231-236.

11. Kanczewska J, Marco S, Vandermeeren C, Maudoux O, Rigaud JL, Boutry M: Activation of the plant plasma membrane $\mathrm{H}^{+}$-ATPase by phosphorylation and binding of 14-3-3 proteins converts a dimer into a hexamer. Proc Natl Acad Sci USA 2005, 102:1 1675-11680.

12. MacKintosh C, Meek SEM: Regulation of plant NR activity by reversible phosphorylation, 14-3-3 proteins and proteolysis. Cell Mol Life Sci 2001, 58:205-214.

13. Shin R, Jez JM, Basra A, Zhang B, Schachtman DP: 14-3-3 Proteins finetune plant nutrient metabolism. FEBS Lett 2011, 585:143-147.

14. Cotelle V, Meek SEM, Provan F, Milne FC, Morrice N, Mackintosh C: 14-3-3s regulate global cleavage of their diverse binding partners in sugarstarved Arabidopsis cells. Embo J 2000, 19:2869-2876.

15. Bachmann M, Huber JL, Athwal GS, Wu K, Ferl RJ, Huber SC: 14-3-3 proteins associate with the regulatory phosphorylation site of spinach leaf nitrate reductase in an isoform-specific manner and reduce dephosphorylation of Ser-543 by endogenous protein phosphatases. FEBS Lett 1996, 398:26-30.

16. Bachmann M, Huber JL, Liao PC, Gage DA, Huber SC: The inhibitor protein of phosphorylated nitrate reductase from spinach (Spinacia oleracea) leaves is a 14-3-3 protein. FEBS Lett 1996, 387:127-131.

17. Huber JL, Huber SC, Campbell WH, Redinbaugh MG: Reversible light/dark modulation of spinach leaf nitrate reductase activity involves protein phosphorylation. Arch Biochem Biophysics 1992, 296:58-65.

18. Sugden C, Donaghy PG, Halford NG, Hardie DG: Two SNF1-Related protein kinases from spinach leaf phosphorylate and inactivate 3-hydroxy-3methylglutaryl-coenzyme A reductase, nitrate reductase, and sucrose phosphate synthase in vitro. Plant Physiol 1999, 120:257-274.

19. Toroser D, Athwal GS, Huber SC: Site-specific regulatory interaction between spinach leaf sucrose-phosphate synthase and 14-3-3 proteins. FEBS Lett 1998, 435:110-114.

20. Kulma A, Villadsen D, Campbell DG, Meek SEM, Harthill JE, Nielsen TH, MacKintosh C: Phosphorylation and 14-3-3 binding of Arabidopsis 6phosphofructo-2-kinase/fructose-2,6-bisphosphatase. Plant J 2004, 37:654-667.
21. Chang IF, Curran A, Woolsey R, Quilici D, Cushman JC, Mittler R, Harmon A, Harper JF: Proteomic profiling of tandem affinity purified 14-3-3 protein complexes in Arabidopsis thaliana. Proteomics 2009, 9:2967-2985.

22. Schauer N, Fernie AR: Plant metabolomics: towards biological function and mechanism. Trends Plant Sci 2006, 11:508-516.

23. Sawada Y, Akiyama K, Sakata A, Kuwahara A, Otsuki H, Sakurai T, Saito K, Hirai MY: Widely targeted metabolomics based on large-scale MS/MS data for elucidating metabolite accumulation patterns in plants. Plant Cell Physiol 2009, 50:37-47.

24. Saito K, Matsuda F: Metabolomics for functional genomics, systems biology, and biotechnology. Annu Rev Plant Biol 2010, 61:463-489.

25. Stitt $M$, Sulpice R, Keurentjes J: Metabolic networks: how to identify key components in the regulation of metabolism and growth. Plant Physiol 2010, 152:428-444

26. Dietrich $P$, Sanders $D$, Hedrich $R$ : The role of ion channels in lightdependent stomatal opening. J Exp Bot 2001, 52:1959-1967.

27. Hirano $T$, Ito A, Berberich T, Terauchi R, Saitoh H: Virus-induced gene silencing of 14-3-3 genes abrogates dark repression of nitrate reductase activity in Nicotiana benthamiana. Mol Genet Genomics 2007, 278:125-133.

28. Zuk M, Weber R, Szopa J: 14-3-3 protein down-regulates key enzyme activities of nitrate and carbohydrate metabolism in potato plants. $J$ Agric Food Chem 2005, 53:3454-3460.

29. Tzin V, Galili G: The biosynthetic pathways for shikimate and aromatic amino acids in Arabidopsis thaliana. In The Arabidopsis book. Edited by: Jander G. Rockville, MD: The American Society of Plant Biologists; 2010:1-18.

30. Agrawal GK, Thelen JJ: Large scale identification and quantitative profiling of phosphoproteins expressed during seed filling in oilseed rape. Mol Cell Proteomics 2006, 5:2044-2059.

31. Gampala SS, Kim TW, He JX, Tang WQ, Deng ZP, Bai MY, Guan SH, Lalonde S, Sun Y, Gendron JM, et al: An essential role for 14-3-3 proteins in brassinosteroid signal transduction in Arabidopsis. Dev Cell 2007, 13:177-189.

32. Schoonheim PJ, Veiga H, Pereira DD, Friso G, van Wijk KJ, de Boer AH: A comprehensive analysis of the 14-3-3 interactome in barley leaves using a complementary proteomics and two-hybrid approach. Plant Physiol 2007, 143:670-683

33. Chung HJ, Sehnke PC, Ferl RJ: The 14-3-3 proteins: cellular regulators of plant metabolism. Trends Plant Sci 1999, 4:367-371.

34. de Boer B: Fusicoccin-A key to multiple 14-3-3 locks? Trends Plant Sci 1997, 2:60-66.

35. Paul AL, Sehnke PC, Ferl RJ: Isoform-specific subcellular localization among 14-3-3 proteins in Arabidopsis seems to be driven by client interactions. Mol Biol Cell 2005, 16:1735-1743.

36. Aducci P, Camoni L, Marra M, Visconti S: From cytosol to organelles: 14-33 proteins as multifunctional regulators of plant cell. lubmb Life 2002, 53:49-55.

37. May T, Soll J: 14-3-3 proteins form a guidance complex with chloroplast precursor proteins in plants. Plant Cell 2000, 12:53-63.

38. Riedel J, Tischner R, Mack G: The chloroplastic glutamine synthetase (GS2) of tobacco is phosphorylated and associated with 14-3-3 proteins inside the chloroplast. Planta 2001, 213:396-401.

39. Sehnke PC, Chung HJ, Wu K, Ferl RJ: Regulation of starch accumulation by granule-associated plant 14-3-3 proteins. Proc Natl Acad Sci USA 2001, 98:765-770.

40. Bunney TD, van Walraven HS, de Boer AH: 14-3-3 protein is a regulator of the mitochondrial and chloroplast ATP synthase. Proc Natl Acad Sci USA 2001, 98:4249-4254.

41. Foyer CH, Lescure JC, Lefebvre C, Morot-Gaudry JF, Vincentz M, Vaucheret H: Adaptations of photosynthetic electron transport, carbon assimilation, and carbon partitioning in transgenic Nicotiana plumbaginifolia plants to changes in nitrate reductase activity. Plant Physiol 1994, 104:171-178.

42. Scheible WR, Gonzalez-Fontes A, Morcuende R, Lauerer M, Geiger M, Glaab J, Gojon A, Schulze ED, Stitt M: Tobacco mutants with a decreased number of functional nia genes compensate by modifying the diurnal regulation of transcription, post-translational modification and turnover of nitrate reductase. Planta 1997, 203:304-319.

43. Lima L, Seabra A, Melo P, Cullimore J, Carvalho H: Phosphorylation and subsequent interaction with 14-3-3 proteins regulate plastid glutamine synthetase in Medicago truncatula. Planta 2006, 223:558-567. 
44. Miflin BJ, Habash DZ: The role of glutamine synthetase and glutamate dehydrogenase in nitrogen assimilation and possibilities for improvement in the nitrogen utilization of crops. J Exp Bot 2002, 53:979-987.

45. Comparot S, Lingiah G, Martin T: Function and specificity of 14-3-3 proteins in the regulation of carbohydrate and nitrogen metabolism. $J$ Exp Bot 2003, 54:595-604.

46. Coruzzi G, Bush DR: Nitrogen and carbon nutrient and metabolite signaling in plants. Plant Physiol 2001, 125:61-64.

47. Nunes-Nesi A, Fernie AR, Stitt M: Metabolic and signaling aspects underpinning the regulation of plant carbon nitrogen interactions. $\mathrm{Mol}$ Plant 2010, 3:973-996.

48. Bustos DM, Iglesias AA: Phosphorylated non-phosphorylating glyceraldehyde-3-phosphate dehydrogenase from heterotrophic cells of wheat interacts with 14-3-3 proteins. Plant Physiol 2003, 133:2081-2088.

49. Swatek KN, Graham K, Agrawal GK, Thelen JJ: The 14-3-3 isoforms chi and epsilon differentially bind client proteins from developing Arabidopsis seed. J Proteome Res 2011, 10:4076-4087.

50. Singh SA, Christendat D: Structure of Arabidopsis dehydroquinate dehydratase-shikimate dehydrogenase and implications for metabolic channeling in the shikimate pathway. Biochem 2006, 45:7787-7796.

51. Smith AM, Zeeman SC, Smith SM: Starch degradation. Annu Rev Plant Biol 2005, 56:73-98.

52. Fritzius T, Aeschbacher R, Wiemken A, Wingler A: Induction of ApL3 expression by trehalose complements the starch-deficient Arabidopsis mutant adg2-1 lacking ApL1, the large subunit of ADP-glucose pyrophosphorylase. Plant Physiol 2001, 126:883-889.

53. Smith SM, Fulton DC, Chia T, Thorneycroft D, Chapple A, Dunstan H, Hylton C, Zeeman SC, Smith AM: Diurnal changes in the transcriptome encoding enzymes of starch metabolism provide evidence for both transcriptional and posttranscriptional regulation of starch metabolism in Arabidopsis leaves. Plant Physiol 2004, 136:2687-2699.

54. Reimann R, Hippler M, Machelett B, Appenroth KJ: Light induces phosphorylation of glucan water dikinase, which precedes starch degradation in turions of the duckweed Spirodela polyrhiza. Plant Physiol 2004, 135:121-128.

55. Ritte G, Scharf A, Eckermann N, Haebel S, Steup M: Phosphorylation of transitory starch is increased during degradation. Plant Physiol 2004, 135:2068-2077.

56. Shin $\mathrm{R}$, Berg $\mathrm{RH}$, Schachtman DP: Reactive oxygen species and root hairs in Arabidopsis root response to nitrogen, phosphorus and potassium deficiency. Plant Cell Physiol 2005, 46:1350-1357.

57. Kusano M, Fukushima A, Arita M, Jonsson P, Moritz T, Kobayashi M, Hayashi N, Tohge T, Saito K: Unbiased characterization of genotypedependent metabolic regulations by metabolomic approach in Arabidopsis thaliana. BMC Syst Biol 2007, 1:53.

58. Jonsson P, Johansson ES, Wuolikainen A, Lindberg J, Schuppe-Koistinen I, Kusano M, Sjostrom M, Trygg J, Moritz T, Antti H: Predictive metabolite profiling applying hierarchical multivariate curve resolution to GC-MS data-a potential tool for multi-parametric diagnosis. J Proteome Res 2006, 5:1407-1414.

59. Stacklies W, Redestig H, Scholz M, Walther D, Selbig J: PCA Methods-a bioconductor package providing PCA methods for incomplete data. Bioinformatics 2007, 23:1164-1167.

60. Redestig H, Fukushima A, Stenlund H, Moritz T, Arita M, Saito K, Kusano M: Compensation for systematic cross-contribution improves normalization of mass spectrometry based metabolomics data. Anal Chem 2009, 81:7974-7980.

61. Eriksson L, Trygg J, Wold S: CV-ANOVA for significance testing of PLS and OPLS (R) models. J Chemometrics 2008, 22:594-600.

62. Gentleman R, Carey V, Dudoit S, Irizarry R, Huber W, Smyth G: LIMMA: linear models for microarray data. In: Bioinformatics and computational biology solutions using $\mathrm{R}$ and Bioconductor. New York: Springer; 2005Chapter 23.

63. Benjamini $Y$, Hochberg A: Controlling the false discovery rate: a practical and powerful approach to multiple testing. J Royal Stat Soc Ser 1995, 57:289-300.

64. Cross JM, von Korff M, Altmann T, Bartzetko L, Sulpice R, Gibon Y, Palacios N, Stitt M: Variation of enzyme activities and metabolite levels in 24 Arabidopsis accessions growing in carbon-limited conditions. Plant Physiol 2006, 142:1574-1588.
65. Nunes-Nesi A, Carrari F, Gibon Y, Sulpice R, Lytovchenko A, Fisahn J, Graham J, Ratcliffe RG, Sweetlove LJ, Fernie AR: Deficiency of mitochondrial fumarase activity in tomato plants impairs photosynthesis via an effect on stomatal function. Plant J 2007, 50:1093-1106.

66. Gibon Y, Blaesing OE, Hannemann J, Carillo P, Hohne M, Hendriks JH, Palacios N, Cross J, Selbig J, Stitt M: A robot-based platform to measure multiple enzyme activities in Arabidopsis using a set of cycling assays: comparison of changes of enzyme activities and transcript levels during diurnal cycles and in prolonged darkness. Plant Cell 2004, 16:3304-3325.

67. Sulpice R, Tschoep H, KMVO N, Bussis D, Usadel B, Hohne M, WituckaWall H, Altmann T, Stitt M, Gibon Y: Description and applications of a rapid and sensitive non-radioactive microplate-based assay for maximum and initial activity of D-ribulose-1,5-bisphosphate carboxylase/ oxygenase. Plant Cell Environ 2007, 30:1163-1175.

68. Burrell MM, Mooney P, Blundy M, Carter D, Wilson F, Green J, Blundy K, Aprees T: Genetic manipulation of 6-phosphofructokinase in potatotubers. Planta 1994, 194:95-101.

69. Manjunath S, Lee CH, VanWinkle P, Bailey-Serres J: Molecular and biochemical characterization of cytosolic phosphoglucomutase in maize. Expression during development and in response to oxygen deprivation. Plant Physiol 1998, 117:997-1006.

70. Keurentjes JJ, Sulpice R, Gibon Y, Steinhauser MC, Fu J, Koornneef M, Stitt $M$, Vreugdenhil D: Integrative analyses of genetic variation in enzyme activities of primary carbohydrate metabolism reveal distinct modes of regulation in Arabidopsis thaliana. Genome Biol 2008, 9:R129.

71. Kuroda H, Takahashi N, Shimada H, Seki M, Shinozaki K, Matsui M: Classification and expression analysis of Arabidopsis F-box-containing protein genes. Plant Cell Physiol 2002, 43:1073-1085.

72. Risseeuw EP, Daskalchuk TE, Banks TW, Liu E, Cotelesage J, Hellmann H, Estelle M, Somers DE, Crosby WL: Protein interaction analysis of SCF ubiquitin E3 ligase subunits from Arabidopsis. Plant J 2003, 34:753-767.

doi:10.1186/1752-0509-5-192

Cite this article as: Diaz et al:: Determining novel functions of

Arabidopsis 14-3-3 proteins in central metabolic processes. BMC Systems Biology 2011 5:192.

\section{Submit your next manuscript to BioMed Central and take full advantage of:}

- Convenient online submission

- Thorough peer review

- No space constraints or color figure charges

- Immediate publication on acceptance

- Inclusion in PubMed, CAS, Scopus and Google Scholar

- Research which is freely available for redistribution

Submit your manuscript at www.biomedcentral.com/submit
C Biomed Central 